\title{
Nutrition and gastric cancer
}

\author{
Carlo La Vecchia MD ${ }^{1,2}$, Silvia Franceschi MD ${ }^{3}$
}

\begin{abstract}
C La Vecchia, S Franceschi. Nutrition and gastric cancer. Can J Gastroenterol 2000;14(Suppl D):51D-54D. The reasons for the worldwide decline in stomach cancer incidence and mortality rates are not fully understood, but dietary changes are clearly implicated. While the possible mechanisms of gastric carcinogenesis and the impact of Helicobacter pylori eradication remain open to debate, at least two practical recommendations - to increase fruit and vegetable intake, and to reduce consumption of salt - are already supported by epidemiological evidence. These dietary recommendations may also be beneficial in the prevention of other cancers and chronic diseases. Promising evidence of a favourable effect of certain vitamins, such as vitamin $\mathrm{C}$ and $\mathrm{E}$ and betacarotene, and minerals, such as selenium, justifies additional investigation.
\end{abstract}

Key Words: Diet; Epidemiology; Gastric cancer; Risk

\begin{abstract}
Alimentation et cancer de l'estomac
RÉSUMÉ : On a enregistré une diminution mondiale de l'incidence du cancer de l'estomac et des taux de mortalité qui y sont associés, mais on ne sait pas trop pourquoi; toutefois, des changements d'habitudes alimentaires ne sont certainement pas étrangers à la situation. Même si des mécanismes possibles de la carcinogenèse de l'estomac et l'incidence de l'éradication d'Helicobacter pylori font encore l'objet de débats, au moins deux recommandations pratiques, soit l'augmentation de la consommation de fruits et de légumes et la diminution de l'apport en sel, sont déjà étayées par des données épidémiologiques. Ces recommandations peuvent également avoir une influence sur la prévention d'autres cancers et de maladies chroniques. Des preuves encourageantes sur l'effet favorable de certaines vitamines, comme les vitamines $\mathrm{C}$ et $\mathrm{E}$ et le bêta-carotène, et de minéraux, comme le sélénium, justifient la poursuite d'autres recherches.
\end{abstract}

G astric cancer incidence and mortality rates have substantially declined over the past few decades (1). However, gastric cancer rates remain relatively high in northern and central Italy, and other areas of central and eastern Europe; this situation, therefore, offers opportunities for research (2).

Within Europe, in the early 1990s, the cancer registries with the highest rates of stomach cancer for both sexes (male 25 to $47 / 100,000$; female 10 to $23 / 100,000$ ) were in eastern Europe (Belarus, Estonia, Latvia), northern and central Italy, and Tyrol, Austria. Central Europe and the United Kingdom had intermediate rates (male 15 to 25/100,000; female five to 10/100,000), whereas gastric cancer incidence rates were low for both sexes in several French and Swiss cancer registries, and Sweden and Denmark (Figure 1).

The highest gastric cancer mortality rate within Europe was in the Russian Federation (male 41.6/100,000; female $17.7 / 100,000$ ), followed by Belarus, Ukraine, Estonia and Lat- via. All eastern European registries (plus Portugal) had high gastric cancer rates, while the lowest gastric cancer mortality rates (male less than 10/100,000; female less than five/100,000) were observed in France, Switzerland, Belgium and several Nordic countries (Figure 2). Italy as a whole had intermediate gastric cancer rates (male 17.1/100,000; female 8.1/100,000); gastric cancer rates were high in the north and centre of the country, but low in the south (3). Gastric cancer rates are low in North America but high in Latin America, China and Japan. Gastric cancer remains the second cause of cancer death worldwide (4).

Although still imprecisely defined, the risk factors for stomach cancer include Helicobacter pylori infection, other factors related to unfavourable socioeconomic conditions, a diet poor in fresh fruit and vegetables and hence in several micronutrients, and poor food preservation $(1,2,4)$. These detrimental factors applied to the diet of most eastern Europen countries, but the reasons for the exceedingly high rates

This article was prepared from a presentation made at the World Congress of Gastroenterology, Vienna, Austria, September 6 to 11, 1998

${ }^{1}$ Istituto di Ricerche Farmacologiche "Mario Negri"; ${ }^{2}$ Istituto di Statistica Medica e Biometria, Università di Milano, Milan; ${ }^{3}$ Centro di Riferimento

Oncologico, Aviano (PN), Italy

Correspondence: Dr Carlo La Vecchia, Istituto di Ricerche Farmacologiche "Mario Negri", Via Eritrea 62, 20157-Milan, Italy.

Telephone +39-02-390141, fax+39-02-33200231, e-mail BONIFACINO@MarionEgro.IT

Received for publication December 7, 1998. Accepted December 16, 1998 


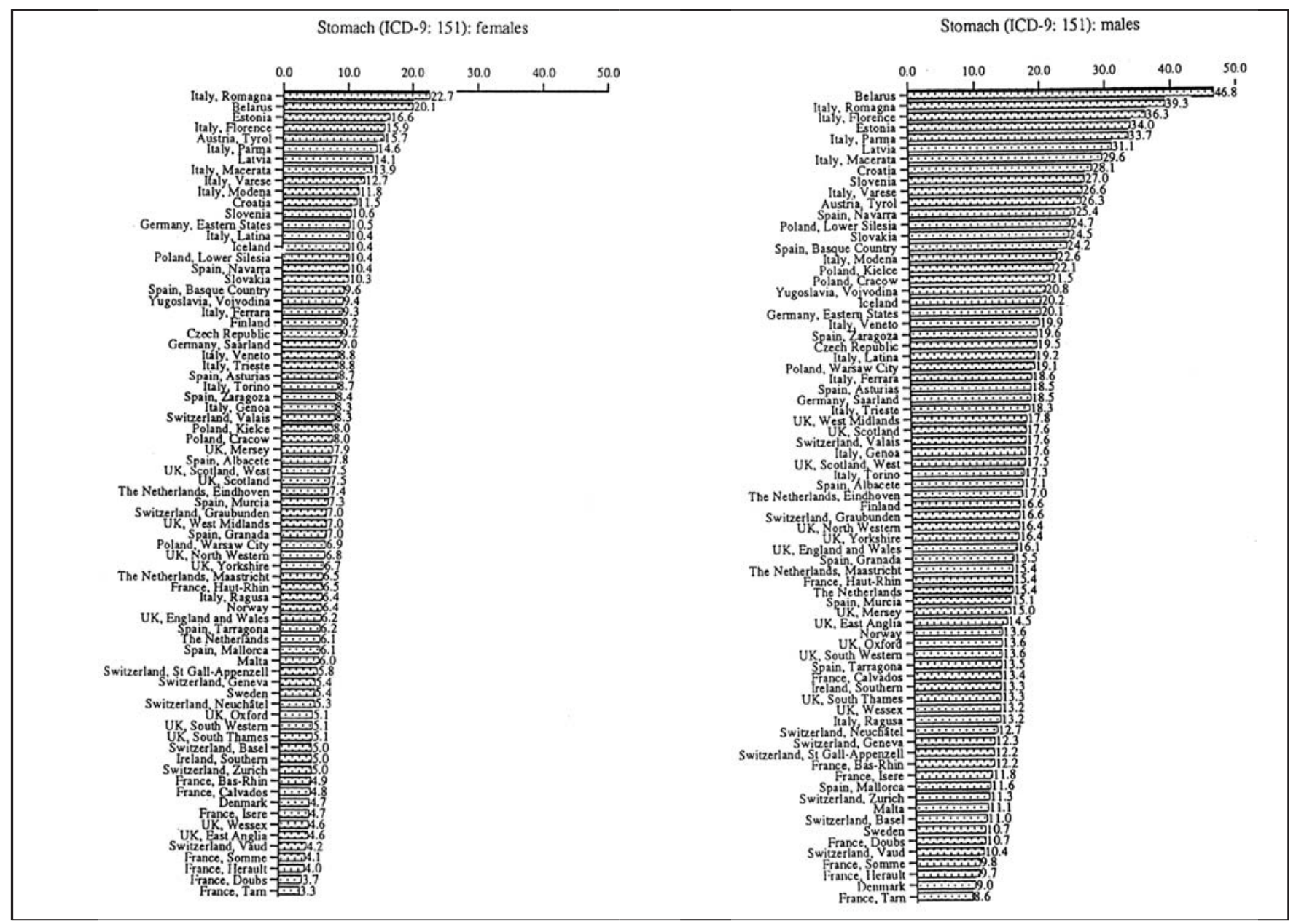

Figure 1) Age-standardized (world standard) incidence rates for stomach cancer in women European cancer registration areas, 1988 to 1992. ICD International Classification of Diseases. Data from reference 3

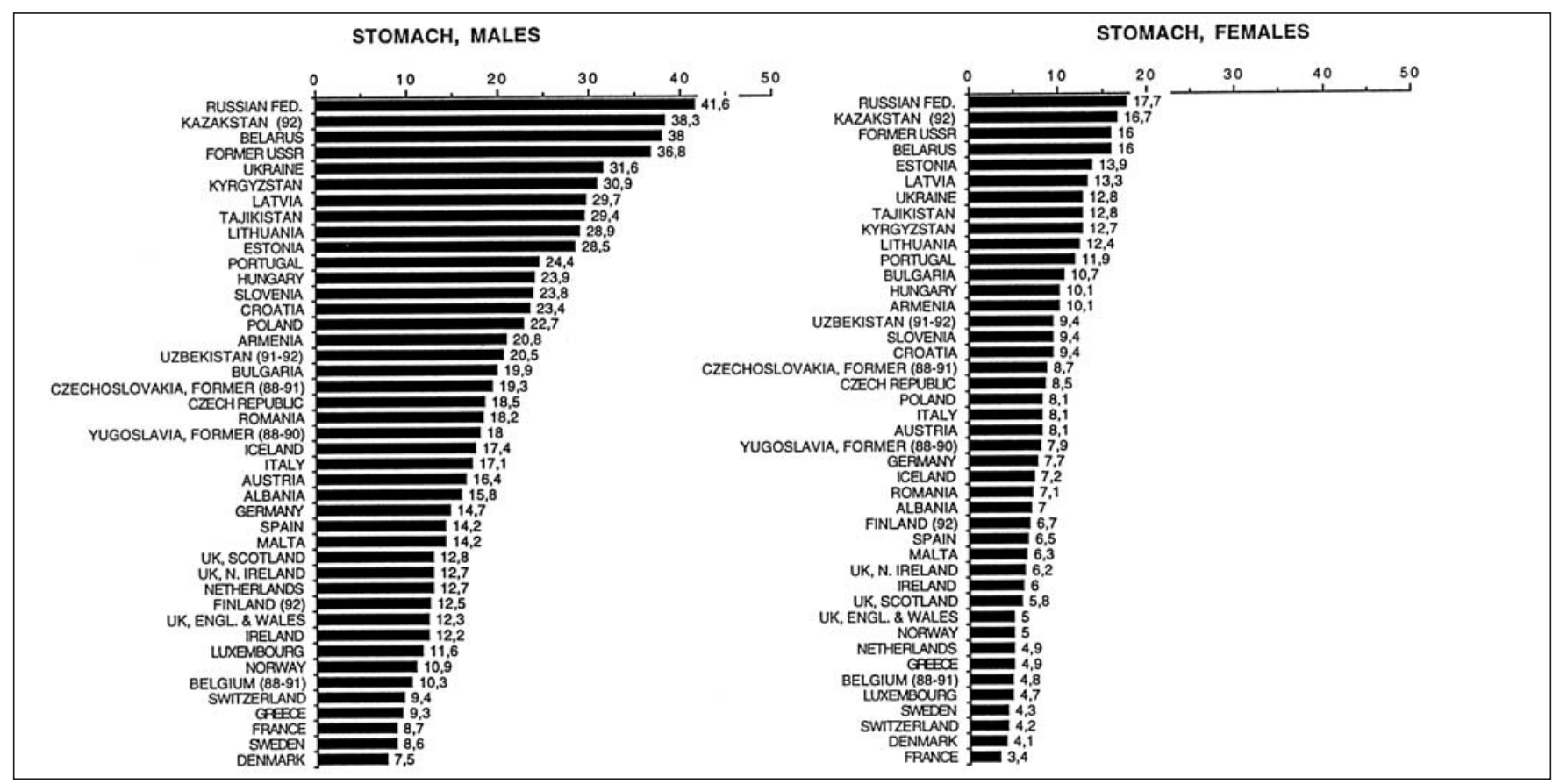

Figure 2) Age-standardized (world standard) mortality rates for stomach cancer in various European countries, 1988 to 1992 . Engl England; N Northern; UK United Kingdom. Data from reference 3 


\section{COPYRIGHT PULSUS GROUP INC, DO NOT COPY}

of gastric cancer in northern and central Italy remain unclear despite considerable research (4-7).

Case-control studies on the etiology of gastric cancer have been conducted in several European countries (2,5-9). Most of them have considered the role of food groups, showing consistently protection from fresh fruits and vegetables. The protective effect of various types of fruits and vegetables, including onion and citrus fruit, was reported by studies from Greece (8) and Italy (5), in which the relative risk (RR) in patients who reported a high consumption of starchy foods and low consumption of fruit and vegetables was elevated almost sevenfold.

These findings have been subsequently reproduced in the largest study of gastric cancer published to date, conducted in seven areas in Italy with different baseline incidence, and including over 1000 cases and 1000 controls $(10,11)$. The $\mathrm{RR}$ ranged between 0.4 and 0.6 for high intakes of various types of fruits, and was 0.6 to 0.8 for high intakes of vegetables. There was also an elevated risk associated with the frequent consumption of traditional foods, such as polenta and pasta $(5,10)$.

In addition to protection from fruit and vegetables, a Belgian study found a direct association between eating meat and starchy foods, including white bread and sugar, and gastric cancer (9). Similar associations with starch and sugar consumption were reported by another Italian study $(5,12)$. Two studies from Spain found elevated risks associated with the consumption of preserved fish, salt, and pickled and smoked foods $(13,14)$. Old-fashioned ways of food preservation, such as the smoking of meat, seemed to be implicated in stomach cancer in a German case-control study (15). High salt intake was shown to increase the risk of stomach cancer in an Italian study (16) and in a Polish (17) investigation.

Taken together, several of these findings indicate the importance of general indicators of a less affluent diet on gastric carcinogenesis. Along this line, the results of a Swedish study suggest that various correlates of unfavourable socioeconomic conditions early in life, such as short height or larger number of siblings, were positively related to subsequent gastric cancer risk (18). A correlate of unfavourable living conditions in the past was the availability of refrigeration, which was inversely related to gastric cancer risk in casecontrol studies from Italy, England and Sweden $(2,19)$.

Epidemiological data on the relation between specific micronutrients and the risk of gastric cancer are scarce but potentially useful in the elucidation of the mechanisms of dietary carcinogenesis. The most consistent patterns of protection from gastric cancer emerged for ascorbic acid, alphatocopherol and beta-carotene $(2,20)$. In an Italian study, after multivariate analysis, the strongest protections, with reference to micronutrients, were observed for beta-carotene and ascorbic acid, and there was a direct association with methionine (20). Ascorbic acid is actively concentrated from the blood in the gastric mucosa and secreted in the gastric lumen cavity, where it can be involved in the detoxification of carcinogens.

In contrast, nitrites seemed to increase gastric cancer
TABLE 1

Percentage attributable risks and $95 \% \mathrm{Cl}$ of stomach cancer in relation to selected risk factors and their combinations. Milan, Italy, 1985 to 1993

\begin{tabular}{lc}
\hline Factor* & $\begin{array}{c}\text { Percentage attributable risk } \\
\mathbf{( 9 5 \%} \mathbf{~ C l )}\end{array}$ \\
\hline Traditional foods & $39.5(26.5,52.6)$ \\
Beta-carotene intake & $47.5(34.0,60.5)$ \\
Vitamin C intake & $15.6(-41,35.3)$ \\
Use of electric refrigerator & $4.6(-38,13.1)$ \\
Low education & $15.4(5.6,25.2)$ \\
Family history of stomach cancer & $4.8(2.4,7.2)$ \\
Traditional foods + & $73.4(34.7,93.5)$ \\
$\quad$ beta-carotene + vitamin C & \\
Traditional foods + electric & $47.9(20.3,75.6)$ \\
$\quad$ refrigerator + low education & \\
*Modified from reference 26 &
\end{tabular}

*Modified from reference 26

risk, with a possible synergism with salt (21). A high intake of salt, nitrites and methionine, which may give rise to 2-chloro-4-methyltiobutanoic acid, was related to a twoto threefold increased risk of gastric cancer (21).

Studies from France and Portugal showed direct associations between gastric cancer and the consumption of red wine, while a study from Poland implicated vodka as a cause of gastric cancer, especially when consumed before breakfast (21). However, the overall evidence from epidemiological studies indicates that alcohol is unlikely to be important in the causation of gastric cancer. Thus, after allowing for other dietary factors, heavy alcohol consumption was not significantly related to gastric cancer risk in a large Italian investigation (22).

In the same study, patients reporting preference for 'hot' foods were at increased risk of stomach cancer, suggesting that thermal irritation may be related to gastric carcinogenesis (23). Food diversity (ie, variety of foods consumed) can, moreover, be a relevant indicator of gastric cancer risk, with relative risk of the order of 0.5 for the most varied diet (24).

In general, dietary correlates were similar for patients with a family history of gastric cancer, suggesting that familial - and hence genetic - and dietary factors have independent effects on gastric carcinogenesis (25). Consequently, any preventive intervention would be more relevant for patients with a family history of gastric cancer.

\section{CONCLUSIONS}

For reasons not fully understood, worldwide stomach cancer incidence and mortality rates have been declining for a long time, and favourable dietary changes are clearly implicated in these trends. The interaction between diet and $H$ pylori infection should be further investigated. The protection offered by the consumption of fruit and vegetables is now the most consistent finding in the diet and gastric cancer issue. Various micronutrients, particularly ascorbic acid and betacarotene, have also been inversely related to gastric cancer 
risk, but the association is generally less consistent than for fruits and vegetables (20).

In terms of population attributable risk, the high intake of traditional starchy foods and low intake of beta-carotene and vitamin $\mathrm{C}$ explained about three-quarters of gastric cancer cases in Northern Italy, thus accounting for most of the excess rate in that population (Table 1) (26).

Thus, while the possible mechanisms of gastric carcinogenesis and the impact of $H$ pylori eradication (27) need to be understood better, at least two practical recommendations - to increase fruit and vegetable intake, and to reduce salt consumption - are already supported by a substantial amount of epidemiological evidence (4). These recommendations are probably beneficial in the prevention of other cancers and chronic diseases, and should be more adequately and specifically emphasized in areas of the world where stomach cancer still is a major public health issue $(1,2,4)$.

ACKNOWLEDGEMENTS: This work was conducted with the contribution of the Italian Association for Cancer Research. The authors thank Mrs M Paola Bonifacino for editorial assistance.

\section{REFERENCES}

1. Howson CP, Hyama T, Wynder EL. The decline in gastric cancer: epidemiology of an unplanned triumph. Epidemiol Rev 1986;8:1-27.

2. Franceschi S, Levi F, La Vecchia C. Epidemiology of gastric cancer in Europe. Eur J Cancer Prev 1994;3S:5-10.

3. Levi F, Lucchini F, Boyle P, Negri E, La Vecchia C. Cancer incidence and mortality in Europe, 1988-92. J Epidemiol Biostat 1998;3:295-361.

4. Nomura A. Stomach cancer. In: Schottenfeld D, Fraumeni JF Jr, eds. Cancer Epidemiology and Prevention. New York: Oxford University Press, 1996:707-24.

5. La Vecchia C, Negri E, Decarli A, et al. A case-control study of diet and gastric cancer in northern Italy. Int J Cancer 1987;40:484-9.

6. Boeing H, Jedrychowski W, Wahrendorf J, Popiela T, Tobiasz-Adamczyk B, Kulig A. Dietary risk factors in intestinal and diffuse types of stomach cancer: a multicenter case-control study in Poland. Cancer Causes Control 1991;2:227-33.

7. La Vecchia C, Ferraroni M, D’Avanzo B, Decarli A, Franceschi S. Selected micronutrient intake and the risk of gastric cancer. Cancer Epidemiol Biomarkers Prev 1994;3:393-8.

8. Trichopoulos D, Ouranos G, Day NE, et al. Diet and cancer of the stomach: a case-control study in Greece. Int J Cancer 1985;36:291-7.
9. Tuyns AJ, Kaas R, Haeltermann M, Riboli E. Diet and gastric cancer. A case-control study in Belgium. Int J Cancer 1992;51:1-6.

10. Buiatti E, Palli D, Decarli A, et al. A case-control study of gastric cancer and diet in Italy. Int J Cancer 1989;44:611-6.

11. Buiatti E, Palli D, Decarli A, et al. A case-control study of gastric cancer and diet in Italy. II. Association with nutrients. Int J Cancer 1990;45:896-901.

12. La Vecchia C, Bosetti C, Negri E, Franceschi S. Refined sugar intake and the risk of gastric cancer. Int J Cancer 1998;78:130-1.

13. Ramon JM, Serra-Majem L, Cerdo C, Oromi J. Dietary factors and gastric cancer risk. A case-control study in Spain. Cancer 1993;71:1731-5.

14. Ramon JP, Serra-Majem L, Cerdo C, Oromi J. Nutrient intake and gastric cancer risk: a case-control study in Spain. Int J Epidemiol 1993;22:983-8.

15. Boeing H, Frentzel-Beyme R, Berger M, et al. Case-control study on stomach cancer in Germany. Int J Cancer 1991;47:858-64.

16. Negri E, La Vecchia C, D'Avanzo B, Gentile A, Boyle P, Franceschi S. Salt preference and the risk of gastrointestinal cancers. Nutr Cancer 1990;14:227-32.

17. Jedrychowski W, Boeing H, Wahrendorf J, et al. Vodka consumption, tobacco smoking and risk of gastric cancer in Poland. Int J Epidemiol 1993;22:606-13.

18. Hansson LE, Baron J, Nyrén O, et al. Early-life risk indicators of gastric cancer. A population-based case-control study in Sweden. Int J Cancer 1994;57:32-7.

19. La Vecchia C, Negri E, D’Avanzo B, Franceschi S. Electric refrigerator use and gastric cancer risk. Br J Cancer $1990 ; 62 ; 136-7$.

20. La Vecchia C, Ferraroni M, D'Avanzo B, Decarli A, Franceschi S. Selected micronutrient intake and the risk of gastric cancer. Cancer Epidemiol Biomarkers Prev 1994;3:393-8.

21. La Vecchia C, Negri E, Franceschi S, Decarli A. Case-control study on influence of methionine, nitrite, and salt on gastric carcinogenesis in Northen Italy. Nutr Cancer 1997;27:65-8.

22. D'Avanzo B, La Vecchia C, Franceschi S. Alcohol consumption and the risk of gastric cancer. Nutr Cancer 1994;22:57-64.

23. La Vecchia C, Negri E, D'Avanzo B, Franceschi S. Food temperature and gastric cancer. Int J Cancer 1990;46:432-4.

24. La Vecchia C, Muñoz SE, Braga C, Fernandez E, Decarli A. Diet diversity and gastric cancer. Int J Cancer 1997;72:255-7.

25. Muñoz SE, Ferraroni M, La Vecchia C, Decarli A. Gastric cancer risk factors in subjects with family history. Cancer Epidemiol Biomarkers Prev 1997;6:137-40.

26. La Vecchia C, D’Avanzo B, Negri E, Decarli A, Benichou J. Attributable risks for stomach cancer in Northern Italy. Int J Cancer 1995;60:748-52.

27. Muñoz N. Is Helicobacter pylori a cause of gastric cancer? An appraisal of the seroepidemiological evidence. Cancer Epidemiol. Biomarkers Prev 1994;3:445-51. 


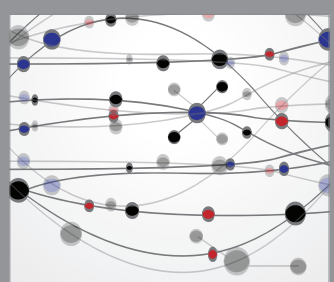

The Scientific World Journal
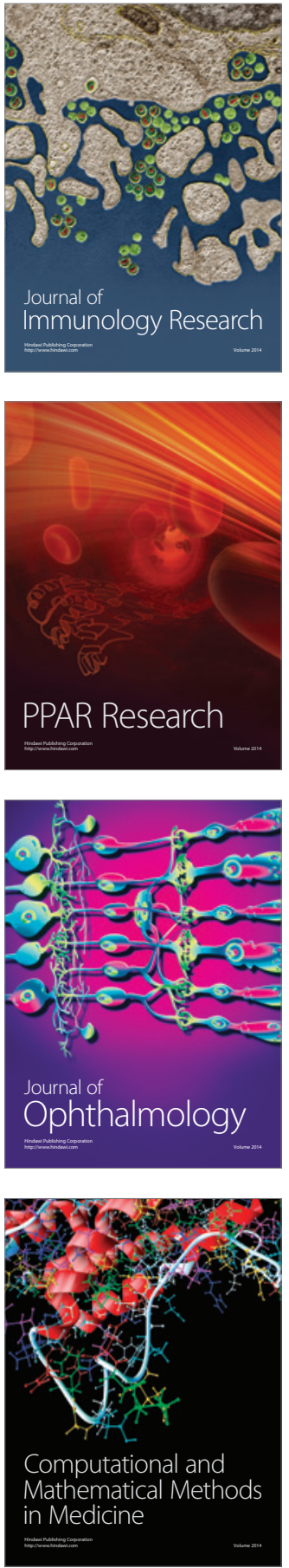

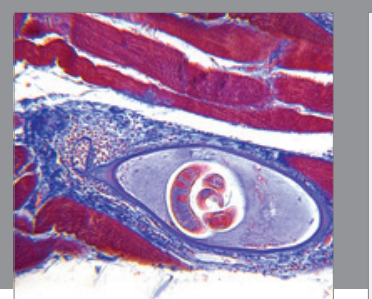

Gastroenterology Research and Practice

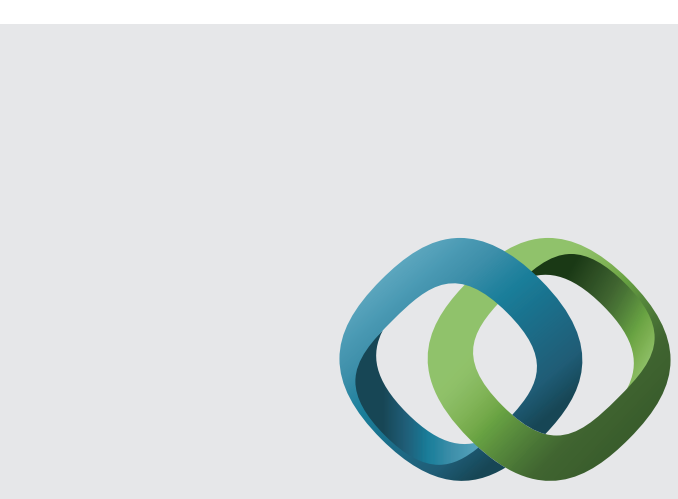

\section{Hindawi}

Submit your manuscripts at

http://www.hindawi.com
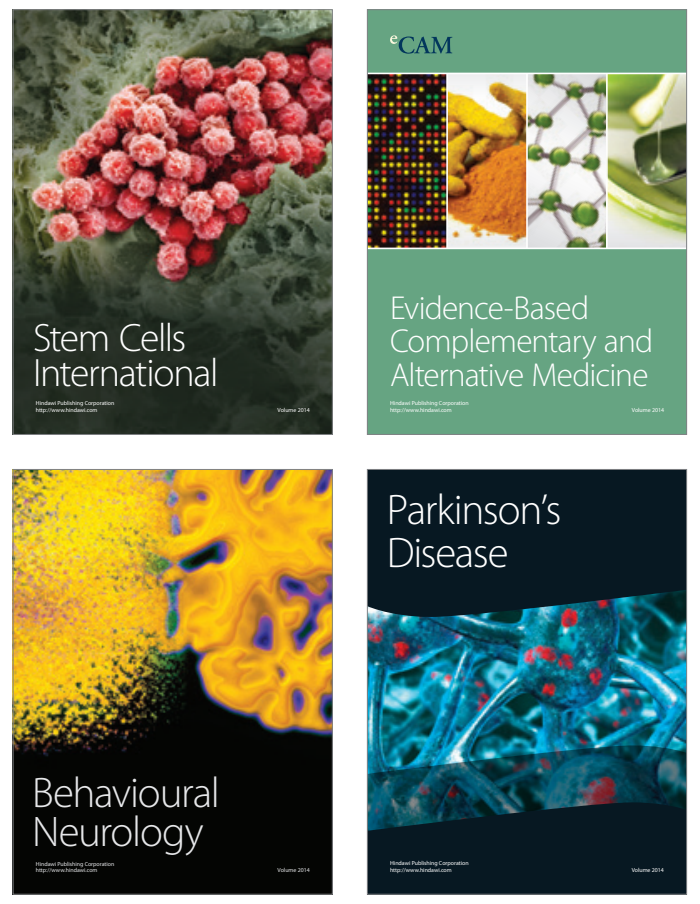
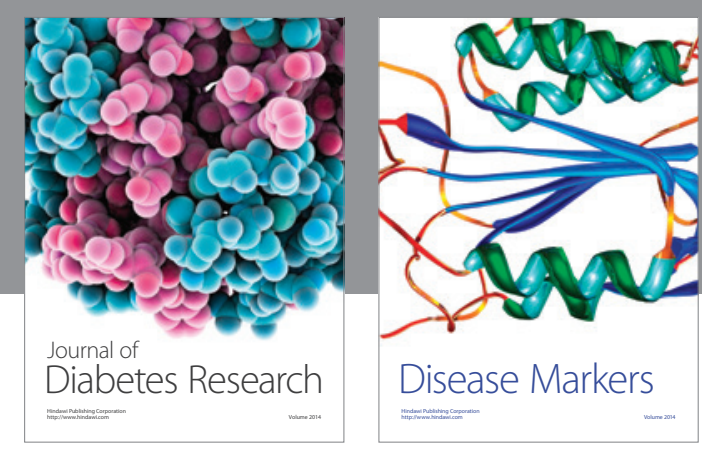

Disease Markers
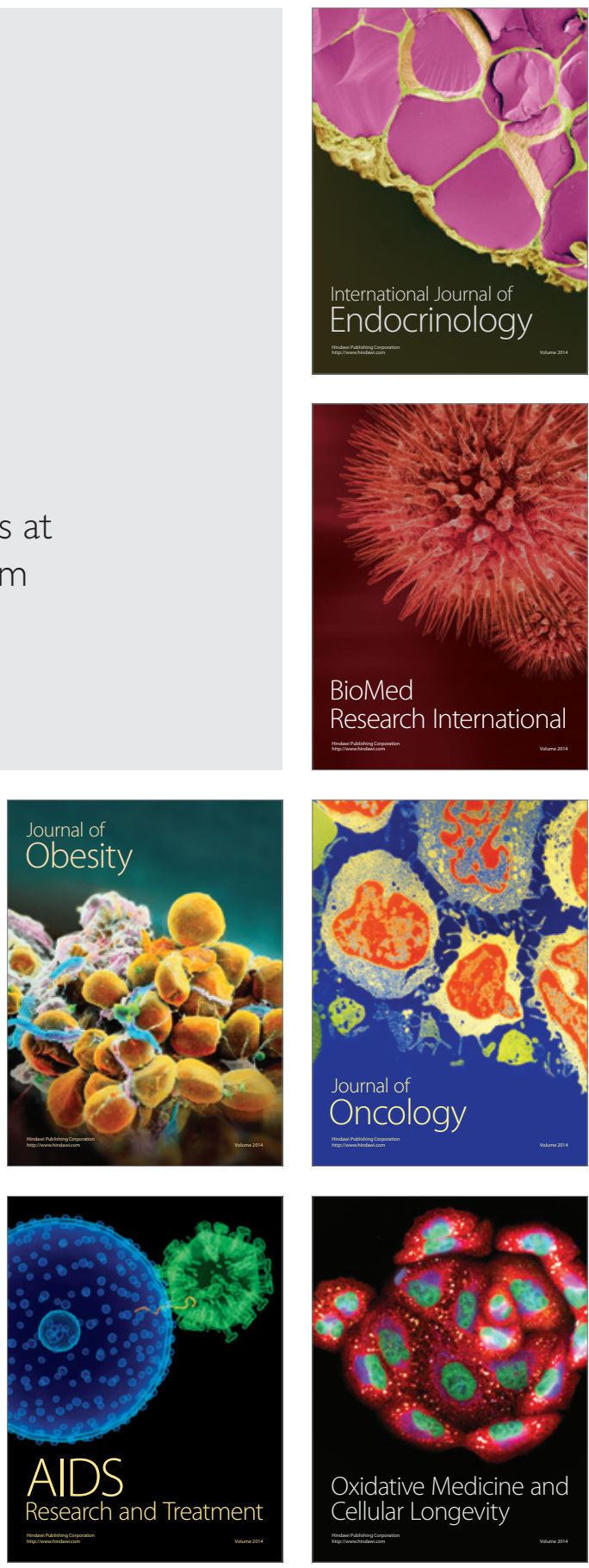